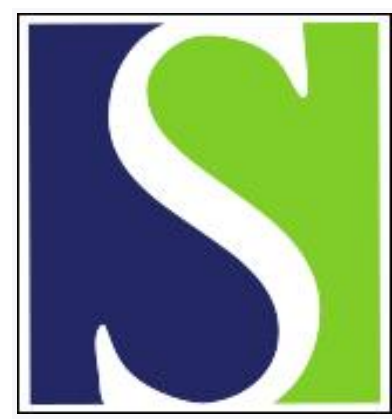

Scand J Work Environ Health 2007;33(6):470-478

https://doi.org/10.5271/sjweh.1173

Issue date: 31 Dec 2007

Cohort mortality study of Swedish pulp and paper mill workers-nonmalignant diseases

by Andersson E, Persson B, Bryngelsson I-L, Magnuson A, Torén K, Wingren $\mathrm{G}$, Westberg $\mathrm{H}$

Affiliation: Sahlgrenska University Hospital, Occupational and Environmental Medicine, Box 414, SE 40530 Göteborg, Sweden.

Eva.Andersson@amm.gu.se

Refers to the following texts of the Journal: 2005;31(1):30-35

1998;24(1):12-17 1999;25(2):85-99 2005;31(4):291-299

The following article refers to this text: 2013;39(2):195-203

Key terms: cardiovascular disease; cohort mortality study; diabetes mellitus; dust; exposure database; myocardial infarction; nonmalignant disease; pulp and paper mill worker; rheumatoid arthritis; shift work; sulfate pulping; sulfite pulping; Sweden

This article in PubMed: www.ncbi.nlm.nih.gov/pubmed/18327516 


\title{
Cohort mortality study of Swedish pulp and paper mill workers- nonmalignant diseases
}

\author{
by Eva Andersson, MD, ${ }^{1}$ Bodil Persson, MD, ${ }^{2}$ Ing-Liss Bryngelsson, BSc, ${ }^{3}$ Anders Magnuson, BSc, ${ }^{4}$ \\ Kjell Torén, MD, ${ }^{1}$ Gun Wingren, PhD, ${ }^{5}$ Håkan Westberg, PhD ${ }^{3}$
}

\begin{abstract}
Andersson E, Persson B, Bryngelsson I-L, Magnuson A, Torén K, Wingren G, Westberg H. Cohort mortality study of Swedish pulp and paper mill workers—nonmalignant diseases. Scand J Work Environ Health. 2007;33(6):470478.
\end{abstract}

Objectives The aim of this study was to determine mortality among pulp and paper mill workers according to the main mill pulping process, department, and gender, particular reference being given to diseases of the circulatory and respiratory systems.

Methods The cohort of 18163 men and 2291 women employed between 1939 and 1999 and with >1 year of employment was followed for mortality from 1952 to 2001 (acute myocardial infarction from 1969). Standardized mortality ratios (SMR) with $95 \%$ confidence intervals (95\% CI) were estimated by comparing the observed number of deaths with the expected number for the entire Swedish population. Exposure was assessed from personnel files in the mills. Data from an exposure measurement database are also presented.

Results There were 5898 deaths in the cohort. Total mortality had an SMR of 1.02 (95\% CI 0.98-1.06) for the men in the sulfate mills and an SMR of 0.93 (95\% CI 0.90-0.97) for the men in the sulfite mills. Mortality from acute myocardial infarction was increased among the men in both the sulfate and sulfite mills [SMR 1.22 (95\% CI 1.12-1.32) and SMR 1.11 (95\% CI 1.02-1.21), respectively] and by department in sulfate pulping (SMR 1.29, 95\% CI 1.07-1.54), paper production (SMR 1.26, 95\% CI 1.06-1.49), and maintenance (SMR 1.16, 95\% CI 1.02-1.30). Mortality from cerebrovascular disease, diabetes mellitus, and nonmalignant respiratory diseases was not increased.

Conclusions Death from acute myocardial infarction, but not cerebrovascular diseases, was increased in this cohort and was probably related to a combination of different occupational exposures (eg, dust, sulfur compounds, shift work, and noise).

Key terms cardiovascular; diabetes mellitus; dust; exposure database; myocardial infarction; rheumatoid arthritis; shift work; sulfate pulping; sulfite pulping.

The production of pulp and paper is an important industrial trade not only in Sweden, but also worldwide. The work environment entails a variety of exposures depending on the process. The pulping processes used have included the alkaline sulfate process, various mechanical processes, the acidic sulfite process, and, also during the last several decades, waste paper pulping. The main occupational exposures in pulping have been wood dust, terpenes, and bleachery chemicals. In sulfate pulping there is also exposure to hydrogen sulfide and other reduced sulfur compounds, and in sulfite pulping there is exposure to sulfur dioxide (1). In paper production, paper dust and different additives are the major exposures. There is a multitude of chemicals in this industry, including some potential carcinogens (2). Other exposures to consider are noise, heat, microorganisms, and shift work.

Several studies have been devoted to morbidity and mortality in the pulp and paper industry, and the results reflect rather vague exposure-response patterns and a lack of consensus regarding risk. There have been reports of increased mortality due to ischemic heart

1 Department of Occupational and Environmental Medicine, Sahlgrenska University Hospital, Göteborg, Sweden.

2 Department of Occupational and Environmental Medicine, University Hospital, Linköping, Sweden.

3 Department of Occupational and Environmental Medicine, Örebro University Hospital, Örebro, Sweden.

4 Statistical and Epidemiology Unit, Center for Clinical Research, Örebro University Hospital, Örebro, Sweden.

5 Division of Occupational and Environmental Medicine, Department of Molecular and Clinical Medicine, Faculty of Health Sciences, Linköping, Sweden.

Reprint requests to: Dr E Andersson, Sahlgrenska University Hospital, Occupational and Environmental Medicine, Box 414, SE 40530 Göteborg, Sweden. [E-mail: Eva.Andersson@amm.gu.se] 
disease among pulp and paper mill workers $(1,3-5)$, but myocardial infarction, specifically, has rarely been studied. Mill workers exposed to sulfur dioxide have been reported to have increased mortality from nonmalignant respiratory diseases and asthma $(6,7)$, and also from lung cancer (8). Even rheumatoid arthritis has been found to be associated with pulp and paper work in a case-referent study from Sweden (9).

With regard to exposure data, an international database has been formed of exposure measurements in the pulp and paper industry (10), and detailed exposure data from paper production (11), as well as data from the nonproduction departments, has been published (12). The database is part of an international study, carried out by the International Agency for Research on Cancer (IARC), on mortality and morbidity in the pulp and paper industry in 13 countries.

This cohort study of four sulfate and four sulfite mills was performed to study the main mill pulping process, and department-specific mortality and morbidity, among Swedish pulp and paper mill workers. Data on mortality in relation to shift work in mills 4 and 5 (3) and cardiovascular mortality until 1992 in mills 1, 2 , and 3 have been published earlier (4). Mills 1-3 were included in the IARC pulp and paper cohort study (8, $13,14)$. With regard to asthma and exposure to sulfur dioxide, results from a questionnaire study for mills 5-8 have also been published earlier (15).

In this paper, we present the cohort, its total mortality, and the cause-specific mortality for nonmalignant causes, as well as some results from the Swedish part of the database of exposure measurements. Cancer mortality and cancer incidence for the cohort will be analyzed and published separately. A specific aim was to study the mortality of acute myocardial infarction and other diseases of the circulatory system according to the main mill pulping process and department. One question considered was whether the sulfite mill workers that were exposed to sulfur dioxide had increased mortality from nonmalignant respiratory diseases.

\section{Study population and methods}

The cohort consisted of two separate Swedish pulp and paper mill cohorts, merged to add statistical power to the analysis. The characteristics of the eight mills and the number of workers included are presented in table 1 for the men and women separately. All but one of the mills are located in rural areas in different parts of Sweden. However, mill 1 is situated in an urban industrial area. An overall inclusion criterion was $>1$ year of employment in the mill.

With regard to mills 1 and 3, only male workers were included. Another inclusion criterion for mills 1-3 was Nordic ethnicity according to name, for follow-up reasons. These mills mainly produced pulp using the sulfate or Kraft process. Mortality was followed from the first inclusion year (1955, 1956, and 1960, respectively) (table 1) to 31 December 2001. The other subcohort, mills 4-8, consisted of one sulfate and four sulfite mills. The inclusion period started earlier (table 1), but only the workers who were alive and had not emigrated by 1952 were included in this mortality study, since the national Causes of Death Register was started at that time. For mill 7, those who had worked exclusively in the period 1965-1968 were lost. The end of the followup for mortality was 1 July 2000.

The mill personnel files provided information on name, date of birth, and also, in most cases, the unique personal identification number of the employees, as well as the date of employment, the date of termination (if

Table 1. Characteristics of the mills and the number of included workers by gender in a cohort of Swedish pulp and paper mill workers. Person-years at risk from 1952 on and the number of deaths are shown by gender and mill. (NSSC = neutral semimechanical)

\begin{tabular}{|c|c|c|c|c|c|c|c|c|c|}
\hline \multirow[t]{3}{*}{ Mill } & \multirow{3}{*}{$\begin{array}{l}\text { Start } \\
\text { of } \\
\text { produc- } \\
\text { tion }\end{array}$} & \multirow{3}{*}{$\begin{array}{c}\text { Years } \\
\text { of } \\
\text { inclusion }\end{array}$} & \multirow[t]{3}{*}{ Process } & \multicolumn{6}{|c|}{ Included } \\
\hline & & & & \multicolumn{3}{|c|}{ Men } & \multicolumn{3}{|c|}{ Women } \\
\hline & & & & $\mathrm{N}$ & $\begin{array}{c}\text { Person- } \\
\text { years }\end{array}$ & $\begin{array}{l}\text { Number } \\
\text { of deaths }\end{array}$ & $\mathrm{N}$ & $\begin{array}{c}\text { Person- } \\
\text { years }\end{array}$ & $\begin{array}{l}\text { Number } \\
\text { of deaths }\end{array}$ \\
\hline 1 & 1918 & $1955-1990$ & Sulfate (sulfite, NSSC ), paper or paperboard & 1829 & 51380 & 441 & - & . & . \\
\hline 2 & 1931 & $1956-1991$ & Sulfate (sulfite, NSSC), paper or paperboard & 3847 & 113684 & 1277 & 778 & 24172 & 154 \\
\hline 3 & 1920 & 1960-1990 & Sulfate, paperboard & 1168 & 29717 & 252 & - & • & • \\
\hline 4 & 1920 & $1940-1999$ & Sulfate, paper & 2543 & 78826 & 1077 & 263 & 7689 & 57 \\
\hline 5 & 1903 & 1942-1999 & Sulfite & 3240 & 88670 & 903 & 471 & 11861 & 48 \\
\hline 6 & 1900 & 1939-1999 & Sulfite, groundwood & 1186 & 34153 & 529 & 138 & 3591 & 31 \\
\hline 7 & 1869 & $1946-1999$ & Sulfite, groundwood, paper & 2585 & 74422 & 899 & 312 & 9064 & 48 \\
\hline 8 & 1960 & 1960-1999 & Sulfite, paper & 1628 & 32142 & 145 & 327 & 6278 & 21 \\
\hline $1-8$ & & & Employed at more than one mill & 137 & 4017 & 16 & 2 & 33 & $\cdot$ \\
\hline All & & & & 18163 & 507011 & 5539 & 2291 & 62689 & 359 \\
\hline
\end{tabular}


applicable), and work history (job titles or departments). The 265 workers with incomplete data for the employment periods were excluded. Information on 20454 workers who fulfilled the inclusion criteria was collected from the mills (table 1). The median year of employment was 1967 (range 1893-1999), and the median duration of employment was 12 (range 1-60) years. Short-term workers, with an employment time of 1-5 years, constituted $30 \%$ of the male workers and $36 \%$ of the female workers. The employees with the longest duration of employment ( $\geq 30$ years) constituted $18.5 \%$ of the men and $4.5 \%$ of the women, respectively. The median age at employment was 24 (range 7-69) years. In the cohort, 137 participants had worked in more than one mill and were gathered into a separate group in table 1, but their person-years were counted according to the mill. Vital status was determined for all of the cohort members. Altogether 14232 were alive and 324 had emigrated by the end of the follow-up. No one was lost to follow-up. At the end of the inclusion, 3808 sulfate and 2337 sulfite mill workers were still employed.

The start of the follow-up for this mortality study was 1952 or, if later, the start of the first included employment. The end of the follow-up was death, emigration, or the last observed date, whichever came first. The cohort was linked to the national Causes of Death Register, and the causes of death have been given here according to the ninth revision of the International Classification of Diseases (ICD 9). Acute myocardial infarction (ICD 410) was not distinguished earlier than 1969. Diabetes mellitus (ICD 250) was classified as being either an underlying or a contributing cause of death.

The total number of person-years of follow-up was 569700 (table 1). The included workers represented

Table 2. Participants (N), person-years at risk, and the number of deaths by department and gender in a Swedish cohort of pulp and paper mill workers.

\begin{tabular}{|c|c|c|c|c|c|c|}
\hline \multirow[t]{3}{*}{ Department ${ }^{\mathrm{a}}$} & \multicolumn{6}{|c|}{ Included } \\
\hline & \multicolumn{3}{|c|}{ Men } & \multicolumn{3}{|c|}{ Women } \\
\hline & N & $\begin{array}{l}\text { Person- } \\
\text { years }\end{array}$ & $\begin{array}{l}\text { Deaths } \\
(\mathrm{N})\end{array}$ & & $\begin{array}{l}\text { Person- } \\
\text { years }\end{array}$ & $\begin{array}{l}\text { Deaths } \\
\text { (N) }\end{array}$ \\
\hline $\begin{array}{l}\text { Wood preparation } \\
(101,102,111)\end{array}$ & 1354 & 439163 & 631 & 39 & 957 & 3 \\
\hline Sulfite pulping (141-149) & 1886 & $6 \quad 56005$ & 638 & 59 & 1453 & 4 \\
\hline Sulfate pulping (151-159) & 1809 & 950655 & 571 & 48 & 1176 & 9 \\
\hline Paper production (201-410) & 3178 & $8 \quad 81104$ & 689 & 570 & 18241 & 140 \\
\hline $\begin{array}{l}\text { Maintenance and } \\
\text { repair (501) }\end{array}$ & 4540 & 0135741 & 1379 & 121 & 2788 & 24 \\
\hline $\begin{array}{l}\text { Steam and power } \\
\text { generation (503) }\end{array}$ & 227 & 5906 & 66 & - & . & . \\
\hline Office (507-510) & 1930 & $0 \quad 55626$ & 635 & 822 & 21108 & 106 \\
\hline Others or unknown & 4697 & 7130881 & 1411 & 722 & 19721 & 86 \\
\hline
\end{tabular}

a Code of the department in parentheses according to the study of the International Agency for Research on Cancer.
318727 years of employment in the mills. The distribution of the employed years of the male workers (representing $92 \%$ of the years), by calendar period, was as follows: $26.6 \%$ for before $1940,14.5 \%$ for $1940-1949$, $13.9 \%$ for $1950-1959,16.1 \%$ for $1960-1969,19.3 \%$ for 1970-1979, 9.6\% for after 1979 .

\section{Exposure assessment}

The participants were first categorized according to the main pulping process of the mill in which they were employed. Then, the department and job title were defined for each period of employment, according to the coding used in the international study of IARC. In our present study, we performed the analysis by department as a proxy for exposure. Wood preparation (IARC codes 101 $\&$ 102) and groundwood pulping (111) were combined as wood preparation. Paper and paperboard production (201-299 \& 301-399) and paper and paperboard product manufacturing (converting operations, 401-410) were combined as paper production. For the included participants and person-years in each department category, see table 2. Analyses were also carried out for the bleaching departments (143\& 153). One participant could contribute person-years to more than one department; accordingly, 1446 participants were employed at two different departments, and 125 had worked at three or more.

As part of our cohort study, the Swedish contribution to the international measurement database for the pulp and paper industry was extracted. It included 3792 air sample concentrations measured in the period 1971 to 1991 in 32 Swedish pulp and paper mills, representing 43 different chemical and biological agents. Exposure measurement data, reflecting agents with potential effects on the circulatory and respiratory system (ie, dust, organosulfur compounds, and sulfur dioxide) are presented. The number of samples, arithmetic means, and standard deviations, as well as the geometric means and the corresponding standard deviations, are shown by department and agent in table 3 . In addition, the fraction of air concentration levels exceeding the current Swedish occupational exposure limits (OEL) and the number of measurements exceeding the detection limits are listed.

\section{Statistical analysis}

The person-years at risk were calculated and stratified according to gender, 5-year age groups, and 1-year calendar periods. The expected numbers of deaths for these strata were calculated with the use of the general Swedish population as reference. Standardized mortality ratios (SMR) with $95 \%$ confidence intervals $(95 \% \mathrm{CI})$ were calculated on the assumption of a Poisson distribution of the observed numbers. Risks according to the main mill 
Table 3. Air sample concentrations of some of the chemical agents in the Swedish database of exposures in the pulp and paper industry in 1971 to 1991 by department-distribution parameters, occupational exposure limits (OEL), percentage of samples exceeding the occupational exposure limits, and the detection limits. $(\mathrm{AM}=$ arithmetic mean, $\mathrm{SD}=$ standard deviation, $\mathrm{GM}=$ geometric mean, $\mathrm{GSD}=$ geometric standard deviation, $\mathrm{DL}=$ detection limit)

\begin{tabular}{|c|c|c|c|c|c|c|c|c|c|}
\hline \multirow[t]{2}{*}{ Agent } & \multirow{2}{*}{$\begin{array}{c}\text { Samples } \\
(\mathrm{N})\end{array}$} & \multicolumn{7}{|c|}{ Air concentrations $\left(\mathrm{mg} / \mathrm{m}^{3}\right)$} & \multirow[b]{2}{*}{$\%>D L$} \\
\hline & & AM & SD & GM & GSD & Range & OEL & $\%>0 E L$ & \\
\hline \multicolumn{10}{|l|}{ Wood preparation } \\
\hline Wood dust & 85 & 2.0 & 2.7 & 1.1 & 3.1 & $0.1-15$ & 2 & 29 & 100 \\
\hline \multicolumn{10}{|l|}{ Sulfite pulping } \\
\hline Sulfur dioxide & 1071 & 9.5 & 13 & 4.5 & 6.3 & $<0.01-160$ & 5 & 57 & 99 \\
\hline \multicolumn{10}{|c|}{ Sulfate pulping or chemical recovery } \\
\hline $\begin{array}{l}\text { Total dust } \\
\text { Calcium oxide } \\
\text { Dimethyl sulfide } \\
\text { Dimethyl disulfide } \\
\text { Dihydrogen sulfide } \\
\text { Methyl mercaptan }\end{array}$ & $\begin{array}{l}79 \\
55 \\
42 \\
42 \\
28 \\
12\end{array}$ & $\begin{array}{r}3.6 \\
4.8 \\
0.6 \\
0.6 \\
34 \\
0.18\end{array}$ & $\begin{array}{r}7.9 \\
8.2 \\
1.0 \\
1.0 \\
83 \\
0.31\end{array}$ & $\begin{array}{r}1.5 \\
0.91 \\
0.3 \\
0.16 \\
0.09 \\
0.09\end{array}$ & $\begin{array}{r}3.7 \\
9.7 \\
3.2 \\
3.3 \\
68 \\
2.3\end{array}$ & $\begin{array}{c}0.1-64 \\
<0.01-48 \\
<0.03-4.5 \\
<0.03-2.6 \\
0-280 \\
<0.04-0.6\end{array}$ & $\begin{array}{r}10 \\
10 \\
2.5 \\
3 \\
14 \\
1\end{array}$ & $\begin{array}{r}7.5 \\
20 \\
7 \\
7 \\
11 \\
0\end{array}$ & $\begin{array}{l}99 \\
98 \\
93 \\
93 \\
89 \\
17\end{array}$ \\
\hline \multicolumn{10}{|l|}{ Paper production } \\
\hline $\begin{array}{l}\text { Paper dust } \\
\text { Total dust } \\
\text { Respirable dust } \\
\text { Inorganic dust }\end{array}$ & $\begin{array}{r}148 \\
201 \\
8 \\
10\end{array}$ & $\begin{array}{r}0.63 \\
5.7 \\
0.55 \\
7.6\end{array}$ & $\begin{array}{r}0.7 \\
7 \\
0.05 \\
12\end{array}$ & $\begin{array}{r}0.41 \\
2.6 \\
0.55 \\
3.4\end{array}$ & $\begin{array}{l}2.5 \\
4.2 \\
1.1 \\
3.6\end{array}$ & $\begin{array}{c}0.07-4.4 \\
0.04-55 \\
0.5-0.6 \\
0.8-39\end{array}$ & $\begin{array}{r}2 \\
10 \\
5 \\
10\end{array}$ & $\begin{array}{r}5 \\
15 \\
0 \\
20\end{array}$ & $\begin{array}{r}90 \\
97 \\
100 \\
100\end{array}$ \\
\hline \multicolumn{10}{|l|}{ Maintenance and repair } \\
\hline Total dust & 13 & 4.6 & 7.6 & 1.1 & 5.8 & $<0.2-26$ & 10 & 15 & 85 \\
\hline
\end{tabular}

pulping process, department, gender, and duration of employment were also calculated. For the female workers, analyses were only carried out according to the main mill pulping process, the departments for paper production, and office work, as there were few female workers in the other departments. The analyses were performed using the computer program Stata (16).

\section{Results}

During the period 1952 to 2001, 5898 deaths occurred in the cohort. The total mortality was decreased (SMR 0.97, 95\% CI 0.94-0.99), and the SMR value for mortality from all malignant neoplasms was 0.95 (95\% CI 0.90-1.00). The male workers in the sulfite mills had a decreased total mortality (table 4). In the results for mortality by department and gender (tables 5 and 6), the male office workers had a decreased total mortality. Restricting the analyses to a duration of employment of $\geq 20$ years did not change the main results (data not shown). However, in the entire cohort, there was a minor change for endocrine diseases, from an SMR of 1.05 (95\% CI 0.87-1.26), based on 116 observed cases, to an SMR of 1.20 (95\% CI 0.93-1.51), based on 69 observed cases.

There was an increased mortality from acute myocardial infarction for the male workers in the pulp and paper mills (SMR 1.16, 95\% CI 1.10-1.23), especially in sulfate mills (SMR 1.22, 95\% CI 1.12-1.32). For all the mills together, the mortality of the women with this diagnosis was similar (SMR 1.16, 95\% CI 0.88-1.51). Even mortality by department was increased for the men in sulfate pulping and maintenance, as well as for those in paper production. The mortality from cerebrovascular diseases [men: SMR 1.00 (95\% CI 0.91-1.09); women: SMR 0.89 (95\% CI 0.64-1.22)] or diabetes mellitus [men: SMR 0.91 (95\% CI 0.82-1.01); women: SMR 0.61 (95\% CI 0.37-0.95)] was not increased in the entire cohort, or in any of the departments. Mortality from acute myocardial infarction was also analyzed for the male workers by department for each main mill pulping process (table 7). The sulfate mill workers employed in sulfate pulping, paper production, and maintenance had an increased risk. Among the sulfite mill workers, the highest risk estimates were calculated for the departments with sulfite pulping and paper production.

Analyzing acute myocardial infarction only for workers under 65 years of age at death gave a slightly higher risk estimate (men: SMR 1.21, 95\% CI 1.071.36). Furthermore, by analyzing two separate periods (1969-1985 \& 1986-2001) for these workers, we found different patterns for the sulfate and sulfite mills. During the first period, the mortality differed [sulfate male workers: SMR 1.41 (95\% CI 1.15-1.71); sulfite male workers: SMR 0.98 (95\% CI 0.77-1.24)], but during 1986-2001 it converged [sulfate male workers: SMR 1.23 (95\%CI 0.97-1.54); sulfite male workers: SMR 1.29 (95\% CI 0.97-1.69)]. The male workers 
Table 4. Standardized mortality ratios (SMR) by diagnostic group, main mill pulping process, and gender for the Swedish pulp and paper mill workers in 1952-2001. ( 0 = observed number of deaths, $95 \% \mathrm{Cl}=95 \%$ confidence interval)

\begin{tabular}{|c|c|c|c|c|c|c|c|c|c|c|c|c|}
\hline \multirow[t]{3}{*}{ Cause of death ${ }^{a}$} & \multicolumn{6}{|c|}{ Sulfate mills } & \multicolumn{6}{|c|}{ Sulfite mills } \\
\hline & \multicolumn{3}{|c|}{ Men } & \multicolumn{3}{|c|}{ Women } & \multicolumn{3}{|c|}{ Men } & \multicolumn{3}{|c|}{ Women } \\
\hline & 0 & SMR & $95 \% \mathrm{Cl}$ & 0 & SMR & $95 \% \mathrm{Cl}$ & 0 & SMR & $95 \% \mathrm{Cl}$ & 0 & SMR & $95 \% \mathrm{Cl}$ \\
\hline All causes & 2875 & 1.02 & $0.98-1.06$ & 202 & 0.93 & $0.81-1.07$ & 2664 & 0.93 & $0.90-0.97$ & 157 & 0.86 & $0.73-1.00$ \\
\hline Infectious and parasitic diseases (1-139) & 14 & 0.54 & $0.29-0.90$ & 2 & 0.98 & $0.12-3.53$ & 24 & 0.95 & $0.62-1.41$ & 5 & 3.00 & $0.97-6.99$ \\
\hline Neoplasms (140-239) & 650 & 0.98 & $0.91-1.06$ & 64 & 0.92 & $0.71-1.18$ & 612 & 0.93 & $0.86-1.01$ & 53 & 0.99 & $0.74-1.29$ \\
\hline $\begin{array}{l}\text { Endocrine, nutritional and metabolic } \\
\text { diseases (240-279) }\end{array}$ & 58 & 1.12 & $0.85-1.45$ & 10 & 2.02 & $0.97-3.72$ & 47 & 0.94 & $0.69-1.25$ & 1 & 0.24 & $0.00-1.34$ \\
\hline Diabetes mellitus (250) ${ }^{\mathrm{b}}$ & 144 & 0.79 & $0.67-0.93$ & 9 & 0.52 & $0.24-0.98$ & 190 & 1.03 & $0.89-1.19$ & 11 & 0.72 & $0.36-1.29$ \\
\hline Mental disorders (290-319) & 41 & 0.85 & $0.61-1.15$ & 6 & 1.16 & $0.43-2.53$ & 48 & 1.11 & $0.83-1.50$ & 5 & 1.28 & $0.41-2.98$ \\
\hline Diseases of the nervous system (320-389) & 30 & 0.80 & $0.54-1.15$ & 3 & 0.76 & $0.16-2.22$ & 28 & 0.81 & $0.54-1.17$ & 4 & 1.36 & $0.37-3.48$ \\
\hline Diseases of the circulatory system (390-459) & 1518 & 1.11 & $1.05-1.16$ & 84 & 0.94 & $0.75-1.16$ & 1387 & 0.95 & $0.90-1.00$ & 69 & 0.84 & $0.65-1.06$ \\
\hline Ischemic heart disease (410-414) & 969 & 1.09 & $1.02-1.16$ & 42 & 0.97 & $0.70-1.30$ & 902 & 0.96 & $0.89-1.02$ & 41 & 1.00 & $0.72-1.36$ \\
\hline Acute myocardial infarction (410) ${ }^{\mathrm{C}}$ & 580 & 1.22 & $1.12-1.32$ & 32 & 1.25 & $0.85-1.76$ & 556 & 1.11 & $1.02-1.21$ & 24 & 1.07 & $0.68-1.59$ \\
\hline Cerebrovascular disease (430-438) & 244 & 1.06 & $0.93-1.20$ & 24 & 1.05 & $0.67-1.56$ & 232 & 0.94 & $0.83-1.07$ & 15 & 0.72 & $0.40-1.19$ \\
\hline Diseases of the respiratory system $(460-519)$ & 130 & 0.79 & $0.66-0.93$ & 15 & 1.20 & $0.67-1.98$ & 171 & 0.96 & $0.82-1.11$ & 8 & 0.73 & $0.32-1.44$ \\
\hline $\begin{array}{l}\text { Chronic obstructive pulmonary disease } \\
\text { and allied conditions (490-496) }\end{array}$ & 51 & 0.90 & $0.67-1.18$ & 6 & 1.29 & $0.47-2.80$ & 47 & 0.80 & $0.59-1.06$ & 5 & 1.42 & $0.46-3.32$ \\
\hline Asthma (493) & 14 & 1.10 & $0.60-1.84$ & 2 & 1.49 & $0.18-5.36$ & 7 & 0.52 & $0.21-1.08$ & 1 & 0.92 & $0.02-5.10$ \\
\hline Diseases of the digestive system (520-579) & 80 & 0.75 & $0.59-0.93$ & 3 & 0.40 & $0.08-1.18$ & 93 & 0.88 & $0.71-1.08$ & 4 & 0.64 & $0.17-1.63$ \\
\hline Genitourinary system (580-629) & 50 & 1.13 & $0.84-1.49$ & - & $\cdot$. & .. & 46 & 0.94 & $0.69-1.26$ & 2 & 0.79 & $0.10-2.84$ \\
\hline Musculoskeletal system (710-739) & 12 & 1.61 & $0.83-2.80$ & 2 & 1.17 & $0.14-4.22$ & 10 & 1.31 & $0.63-2.40$ & - & .. & .. \\
\hline Rheumatoid arthritis (714) & 4 & 1.39 & $0.38-3.57$ & 2 & 2.53 & $0.31-9.13$ & 5 & 1.62 & $0.53-3.79$ & - & .. & $\cdot \cdot$ \\
\hline External causes (E800-999) & 262 & 1.00 & $0.88-1.12$ & 9 & 0.71 & $0.32-1.34$ & 171 & 0.77 & $0.66-0.89$ & 4 & 0.41 & $0.11-1.04$ \\
\hline Suicide (E950-959) & 89 & 0.94 & $0.75-1.16$ & 2 & 0.41 & $0.05-1.46$ & 37 & 0.47 & $0.33-0.65$ & 2 & 0.56 & $0.07-2.03$ \\
\hline
\end{tabular}

a Code of the International Classification of Diseases, ninth revision, in parentheses.

${ }^{b}$ Underlying + contributing.

c 1969-2001.

over 65 years of age shared more similar estimates according to the time periods and the main mill pulping processes.

The data for the smaller departments have not been tabulated. The bleachery department (men: 25 deaths among the 146 participants included, 4461 person-years) showed mortality risks for acute myocardial infarction that were similar to that of the other departments [SMR 1.28 (95\% CI 0.51-2.63), based on 7 observed cases]. The steam and power generating plant (men: 66 deaths among the 227 participants included, 5906 person-years) showed no increased mortality from acute myocardial infarction [SMR 1.01 (95\% CI 0.54-1.73), based on 13 cases].

Mortality from asthma or other nonmalignant respiratory diseases was not increased among the male sulfate or sulfite mill workers. There was no case of asthma-related death among the workers in the bleachery department.

Insignificant, but rather high, risk estimates for death from rheumatoid arthritis were found in several departments (tables 5 and 6). External causes of death, along with suicides, were not increased and were even decreased among the male workers in the sulfite mills when they were compared with the general population. In general, the mortality of the sulfite mill workers or sulfite pulping workers was no higher than that of the sulfate mill workers or workers in other departments.

In the Swedish database of exposure measurements, especially the measurements of sulfur dioxide and wood dust exceeded the occupational exposure limits (table 3). From the mills included in our study, some 1335 measurements were collected. The sulfur dioxide samples from the sulfite pulping departments comprised the greater part; the air concentrations ranged from 0.01 to $158 \mathrm{mg} / \mathrm{m}^{3}$ with an arithmetic mean of $9.5 \mathrm{mg} / \mathrm{m}^{3}$. Paper dust was also determined, in particular in the paper production department, and the concentration levels varied from 0.07 to 3.3 (arithmetic mean 0.82 ) $\mathrm{mg} / \mathrm{m}^{3}$.

\section{Discussion}

This Swedish cohort study supports earlier indications of fatal cardiovascular effects among pulp and paper mill 
Table 5. Standardized mortality ratios (SMR) by diagnostic group and department for male workers in Swedish pulp and paper mills in 1952-2001. ( 0 = observed deaths, $95 \% \mathrm{Cl}=95 \%$ confidence intervals)

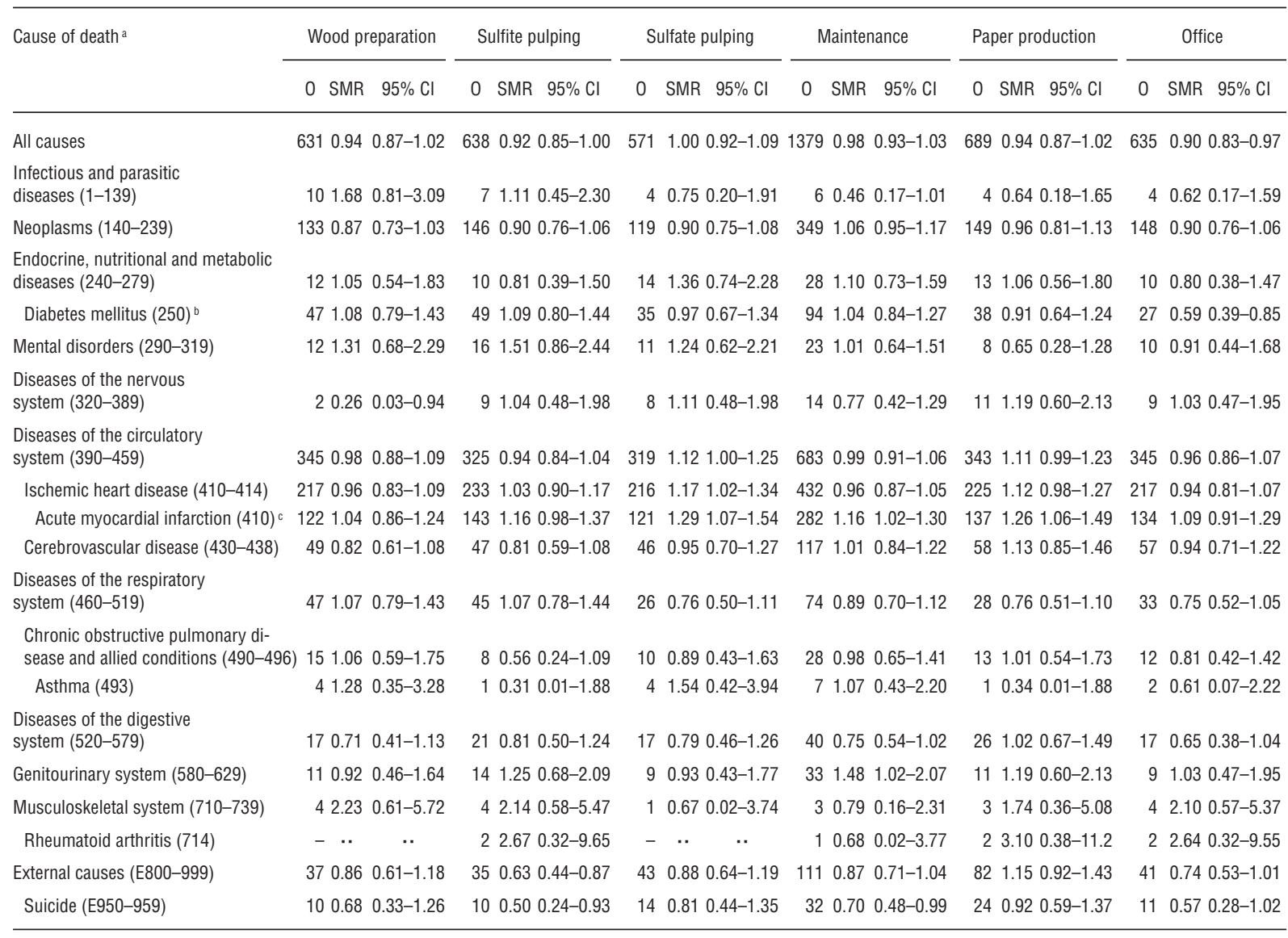

${ }^{a}$ Code of the International Classification of Diseases, ninth revision, in parentheses.

b Underlying+contributing.

c 1969-2001.

workers. The most pronounced finding was the increased risk for acute myocardial infarction, while mortality from cerebrovascular diseases was not increased. The latter finding and the seemingly higher risk among workers under 65 years of age suggest a rather short latency and indicate occupational risk factors. Workers in several departments were at risk, especially those in the sulfate mills.

With the exception of the IARC studies, this is one of the largest cohort studies to be published on pulp and paper mills, due to the size and the long period of follow-up. The Scandinavian countries are recognized for their high-quality registers regarding both mortality and cancer morbidity.

The "healthy worker effect" is often prevalent in industrial cohorts, giving a lower total mortality when comparisons are made with the general population (17, 18). A deficit for cardiovascular deaths tends to contribute most to the effect. In this cohort, the effect was noted for diabetes mellitus (SMR 0.89, 95\% CI 0.80-0.98) and nonmalignant respiratory diseases (SMR 0.88,
95\% CI .79-0.98), but not for cardiovascular diseases, for which, instead, an increased risk for acute myocardial infarction appeared.

Our finding is based on more than 1000 deaths from acute myocardial infarction during a 33-year period of observation. Moreover, diagnostic bias was unlikely to prevail since the cohort was geographically spread all over Sweden, with many physicians involved in confirming the causes of deaths. Exposure was assessed by department and could have been subject to misclassification. One consideration could be that there were few changes registered between departments and there could have been more changes than those noted. However, such a situation would probably be more common among those not registered in any specified department. Many of the workers were skilled, and there were probably more changes within than between departments. Exposure misclassification in this study was regarded as nondifferential. Measurement data from Swedish pulp and paper mills were sparse before 1970, and many of the employment years of the male workers are from 
Table 6. Standardized mortality ratios (SMR) by diagnostic group and department for female workers in Swedish pulp and paper mills in 1952-2001. [0 = observed deaths, $95 \% \mathrm{Cl}=95 \%$ confidence intervals]

\begin{tabular}{|c|c|c|c|c|c|c|}
\hline \multirow{2}{*}{ Cause of death a } & \multicolumn{3}{|c|}{ Paper production } & \multicolumn{3}{|c|}{ Office } \\
\hline & 0 & SMR & $95 \% \mathrm{Cl}$ & 0 & SMR & $95 \% \mathrm{Cl}$ \\
\hline All causes & 140 & 0.97 & $0.82-1.15$ & 106 & 0.91 & $0.74-1.10$ \\
\hline Infectious and parasitic diseases (1-139) & - & $\cdot \cdot$ & $\because$ & 4 & 3.67 & $1.00-9.38$ \\
\hline Neoplasms (140-239) & 42 & 0.99 & $0.71-1.34$ & 35 & 0.92 & $0.64-1.28$ \\
\hline Endocrine, nutritional and metabolic diseases (240-279) & 7 & 2.14 & $0.86-4.42$ & 1 & 0.37 & $0.01-2.07$ \\
\hline Diabetes mellitus (250) ${ }^{\mathrm{b}}$ & 8 & 0.67 & $0.29-1.32$ & 6 & 0.63 & $0.23-1.38$ \\
\hline Mental disorders (290-319) & 3 & 0.85 & $0.17-2.48$ & 4 & 1.62 & $0.44-4.15$ \\
\hline Diseases of the nervous system (320-389) & 1 & 0.42 & $0.01-2.33$ & 4 & 1.89 & $0.52-4.85$ \\
\hline Diseases of the circulatory system (390-459) & 65 & 1.02 & $0.78-1.30$ & 40 & 0.83 & $0.59-1.13$ \\
\hline Ischemic heart disease (410-414) & 33 & 1.06 & $0.73-1.48$ & 23 & 0.96 & $0.61-1.44$ \\
\hline Acute myocardial infarction (410) c & 24 & 1.35 & $0.86-2.01$ & 16 & 1.14 & $0.65-1.85$ \\
\hline Cerebrovascular disease (430-438) & 15 & 0.93 & $0.52-1.53$ & 11 & 0.89 & $0.45-1.60$ \\
\hline Diseases of the respiratory system (460-519) & 11 & 1.26 & $0.63-2.26$ & 9 & 1.37 & $0.62-2.59$ \\
\hline Chronic obstructive pulmonary disease and allied conditions (490-496) & 5 & 1.72 & $0.56-4.01$ & 6 & 2.46 & $0.90-5.35$ \\
\hline Asthma (493) & 2 & 2.33 & $0.28-8.41$ & 2 & 2.70 & $0.33-9.75$ \\
\hline Diseases of the digestive system (520-579) & 2 & 0.41 & $0.05-1.47$ & 4 & 0.99 & $0.27-2.53$ \\
\hline Genitourinary system (580-629) & 1 & 0.42 & $0.01-2.33$ & - & . & .. \\
\hline Musculoskeletal system (710-739) & - & $\cdot \cdot$ & $\cdot \cdot$ & 1 & 1.08 & $0.03-6.00$ \\
\hline Rheumatoid arthritis (714) & - & .. & $\cdot$. & 1 & 2.28 & $0.06-12.7$ \\
\hline External causes (E800-999) & 5 & 0.70 & $0.23-1.62$ & 3 & 0.42 & $0.09-1.22$ \\
\hline Suicide (E950-959) & 1 & 0.39 & $0.01-2.15$ & 1 & 0.35 & $0.01-1.97$ \\
\hline
\end{tabular}

a Code of the International Classification of Diseases, ninth revision, in parentheses.

b Underlying+contributing.

c 1969-2001.

Table 7. Standardized mortality ratios (SMR) for acute myocardial infarction by department and the main mill pulping process among Swedish male pulp and paper mill workers. $(0=$ observed number of deaths, $95 \% \mathrm{Cl}=95 \%$ confidence intervals).

\begin{tabular}{|c|c|c|c|c|c|c|}
\hline \multirow[t]{2}{*}{ Department ${ }^{\mathrm{a}}$} & \multicolumn{3}{|c|}{ Sulfate mills } & \multicolumn{3}{|c|}{ Sulfite mills } \\
\hline & 0 & SMR & $95 \% \mathrm{Cl}$ & 0 & SMR & $95 \% \mathrm{Cl}$ \\
\hline All departments & 580 & 1.22 & $1.12-1.32$ & 556 & 1.11 & $1.02-1.21$ \\
\hline $\begin{array}{l}\text { Wood } \\
\text { preparation }(101,102,111)\end{array}$ & 54 & 1.11 & $0.83-1.45$ & 68 & 0.99 & $0.77-1.25$ \\
\hline Sulfite pulping (141-149) & 11 & 1.11 & $0.56-1.99$ & 132 & 1.17 & $0.98-1.38$ \\
\hline Sulfate pulping (151-159) & 121 & 1.29 & $1.07-1.54$ & - &.. & .. \\
\hline $\begin{array}{l}\text { Paper } \\
\text { production (201-410) }\end{array}$ & 94 & 1.29 & $1.04-1.58$ & 43 & 1.20 & $0.87-1.61$ \\
\hline Maintenance (501) & 156 & 1.21 & $1.03-1.41$ & 126 & 1.09 & $0.92-1.30$ \\
\hline $\begin{array}{l}\text { Others or } \\
\text { unknown (not office) }\end{array}$ & 148 & 1.40 & $1.19-1.65$ & 144 & 1.09 & $0.92-1.28$ \\
\hline
\end{tabular}

a Code of department in parentheses according to the study of the International Agency for Research on Cancer.

that time period. Systematic changes in the production and ventilation facilities took place primarily from the mid-1970s and throughout the 1980s, suggesting that air concentration levels from the early 1970s would reflect the work environment in the 1950s and 1960s. In a cohort study in which multiple outcomes are studied, there should always be concern about random significances, but the mortality from cardiovascular diseases and acute myocardial infarction by department seems consistent.

Most pulp and paper mill mortality studies have been devoted to cancer, but some have reported cardiovascular mortality as well. In a Finnish study, the pattern for ischemic heart disease by department was similar to that of our study (sulfite: SMR 131; sulfate: SMR 142; paper: SMR 138; and maintenance: SMR 118), but in that study power plant workers were also at increased risk (SMR 158) (19). In earlier analyses of a subcohort (mills 1-3), we found increased mortality for workers in sulfate digestion and steam and power generation (4). Matanoski et al (20) found a slightly increased risk for ischemic heart disease among workers in semichemical and soda process mills, but not in sulfate mills, in an internal comparison of their cohort. Some other studies on pulp and paper mill workers have not only reported an increased (21-22) but also a decreased risk for cardiovascular mortality (23-27). A recent published study on nonmalignant mortality among female pulp and paper mill workers showed increased mortality for ischemic heart disease (SMR 1.22, 95\% CI 1.03-1.43), but the highest risk occurred for short-term workers in the paper department (5). In that study, mortality from cerebrovascular diseases was insignificantly increased (SMR 1.16, 95\% CI 0.94-1.42). 
The increased mortality due to ischemic heart disease, reported for pulp and paper mill workers, could be due to several occupational exposures or a mixture of them. Shift work, reduced sulfur compounds, dust, and small particles have been proposed as being the cause $(1,3,4,6)$. Other factors that may affect ischemic heart disease are occupational noise, psychosocial factors, and smoking. However, only the chemical risk factors are reflected in the exposure measurements. Exposure to reduced organosulfur compounds almost exclusively appeared in the sulfate pulping department, and it exceeded the occupational exposure limit in 10-20\% of the samples in the Swedish measurement database. Sulfite mill workers are exposed to sulfur dioxide, which could possibly be a risk factor. There seems to be a short-term effect of sulfur dioxide air pollution levels with respect to ischemic heart diseases (28). In the IARC cohort of pulp and paper mill workers, mortality was reported for the workers exposed to sulfur dioxide (8). Among the workers never exposed, the mortality from diseases of the circulatory system reached an SMR value of 0.92 (95\% CI 0.87-0.96), and for highly exposed workers the SMR was 0.96 (95\% CI 0.86-1.07).

The dust concentrations ranged from 0.04 to 3.3 $\mathrm{mg} / \mathrm{m}^{3}$ in the mills included in this study (data from the exposure measurement database, not shown). There were no data available on the exposure to fine particle fractions. In the ambient air, the effect of these particles on cardiovascular diseases, along with the mechanisms behind them, has been frequently investigated $(29,30)$. Whether occupational exposure to particulate air pollution or dust increases cardiovascular disease has not been studied very much. Recently, a report indicated that male construction workers exposed to inorganic dust had an increased risk of ischemic heart disease, but not an increase in cerebrovascular disease (31).

The increased risk of myocardial infarction concerned workers from several departments, and general exposures in the mills, such as shift work, noise, and psychosocial factors, should also be considered. Shift workers have an estimated $40 \%$ excess risk of cardiovascular disease when compared with day workers (32). Studies analyzing shift work among pulp and paper mill workers have shown an increased risk of ischemic heart disease, as well as risk factors for metabolic syndrome $(3,33,34)$. Occupational noise exposure increases the risk of hypertension (35) and probably also that of ischemic heart disease (36). In a Finnish register study, the job exposures with the most influence on cardiovascular mortality were high workload, low job control, noise, and shift work (37).

Unfortunately, we had no information on smoking habits in our study. Lung cancer risk can be used as a proxy for assessing smoking differences between the studied group and the reference population. The lung cancer mortality of the men in this cohort was not increased overall (SMR 0.95, 95\% CI 0.83-1.08), neither according to the main mill pulping process nor according to department. It is unlikely that the increased mortality from acute myocardial infarction would be explained by smoking habits. In mills 4-8, the cohort members working in the mills after 1970 and alive in 2000 received a mailed questionnaire with items such as nicotine use, smoking, and snuff use (smokeless tobacco). According to the answers $48 \%$ were ever-smokers and $33 \%$ were ever-snuffers, but, by the year $2000,12.8 \%$ were current smokers. Never-smoking was more frequent among the workers born in 1960 and later.

There was no generally increased mortality from nonmalignant respiratory diseases found in this study, even if we know that, in mills 5-8, there was an increased incidence of asthma (15) and chronic bronchitis among the workers exposed to irritant gases. In the IARC pulp and paper mill study of mortality among workers exposed to sulfur dioxide, there was no increased risk from bronchitis, emphysema, and asthma, when analyzed together (7). However, these diagnoses are rarely underlying causes of death.

In a former case-referent study on rheumatoid arthritis, pulp and paper workers were shown to have an increased risk (8). The authors related their finding to occupational exposure to respirable organic dust. Our finding supports these results and ought to be the subject for further study.

In conclusion, the main outcome of this study was an increased risk for acute myocardial infarction that may be caused by various occupational exposures, such as dust and small particles, different sulfur compounds, shift work, and noise, probably in combination. No such effect was shown for cerebrovascular diseases.

\section{Acknowledgments}

This study was supported by the Swedish Council for Worklife Research.

We would like to express our gratitude to Malte Nordqvist for his technical assistance.

\section{References}

1. Torén K, Hagberg S, Westberg H. Health effects of working in pulp and paper mills: Exposure, obstructive airways diseases, hypersensitivity reactions and cardiovascular diseases. Am J Ind Med. 1996;29(2):111-22.

2. Kauppinen T, Teschke K, Astrakianakis G, Boffetta P, Colin $\mathrm{D}$, Keefe A, et al. Assessment of exposure in an international study on cancer risks among pulp, paper, and paper product 
workers. Am Ind Hyg Assoc J. 2002;63(3):254-61.

3. Karlsson B, Knutsson A, Alfredsson L, Andersson E, Torén K. Total mortality and cause-specific mortality of Swedish shift- and dayworkers in pulp and paper industry in 1952-2001 Scand J Work Environ Health. 2005;31(1):30-5.

4. Persson B, Magnusson A, Westberg H, Andersson E, Torén K, Wingren G, et al. Cardiovascular mortality among Swedish pulp and paper mill workers. Am J Ind Med. 2007;50(3):2216.

5. Langseth H, Kjærheim K. Mortality from non-malignant diseases in a cohort of female pulp and paper workers in Norway. Occup Environ Med. 2006;63(11):741-5.

6. Jäppinen $\mathrm{P}$, Tola S. Cardiovascular mortality among pulp mill workers. Br J Ind Med. 1990;47(4):259-62.

7. Andersson E, Nilsson T, Persson B, Wingren G, Torén, K. Mortality from asthma and cancer among sulfite mill workers. Scand J Work Environ Health. 1998;24(1):12-7.

8. Lee WJ, Teschke K, Kauppinen T, Andersen A, Jäppinen P, Szadkowska-Stanczyk I, et al. Mortality from lung cancer in workers exposed to sulfur dioxide in the pulp and paper industry. Environ Health Perspect. 2002;110(10):991-5.

9. Olsson ÅR, Skogh T, Axelson O, Wingren G. Occupations and exposures in the work environment as determinants for rheumatoid arthritis. Occup Environ Med. 2004;61(3):233-8.

10. Kauppinen T, Teschke K, Savela A, Kogevinas M, Boffetta P. International database of exposure measurements in the pulp, paper and paper product industries. Int Arch Occup Environ Health. 1997;70(2):119-27.

11. Korhonen K, Liukkonen L, Ahrens W, Astrakianakis G, Boffetta P, Burdorf A, et al. Occupational exposure to chemical agents in the paper industry Int Arch Occup Environ Health. 2004 77(7):451-60.

12. Teschke K, Ahrens W, Andersen A, Boffetta P, Fincham S, Finkelstein $\mathrm{M}$, et al. Occupational exposure to chemical and biological agents in the nonproduction departments of pulp, paper, and paper product mills: an international study. Am Ind Hyg Assoc J. 1999;60(1):73-83.

13. Carel R, Boffetta P, Kauppinen T, Teschke K, Andersen A, Jäppinen $\mathrm{P}$, et al. Exposure to asbestos and lung and pleural cancer mortality among pulp and paper industry workers. J Occup Environ Med. 2002;44(6):579-84.

14. McLean D, Pearce N, Langseth H, Jäppinen P, SzadkowskaStanczyk I, Persson B, et al. Cancer mortality in workers exposed to organochlorine compounds in the pulp and paper industry: an international collaborative study. Environ Health Perspect. 2006;114 (7):1007-12.

15. Andersson E, Knutsson A, Hagberg S, Nilsson T, Karlsson $\mathrm{B}$, Alfredsson L, et al. Incidence of asthma among workers exposed to sulfur dioxide and other irritant gases. Eur Resp J. 2006;27(4):720-5.

16. Stata Corp. Stata Statistical Software: release 8. College Station (TX): Stata Corp LP; 2005.

17. McMichael AJ. Standardized mortality ratios and the "healthy worker effect": scratching beneath the surface. J Occup Med. 1976;18(3):165-8.

18. Checkoway H, Pearce N, Kriebel D. Research methods in occupational epidemiology. 2nd edition. Oxford (United Kingdom): Oxford University Press; 2004. Monographs in Epidemiology and Biostatistics, volume 34.

19. Jäppinen P. A mortality study of Finnish pulp and paper workers. Br J Ind Med. 1987;44(9):580-7.

20. Matanoski GM, Kanchanaraksa S, Lees PSJ, Tao X-G, Royall
$\mathrm{R}$, Francis M, et al. Industry-wide study of mortality of pulp and paper mill workers. Am J Ind Med. 1998;33(4):354-65.

21. Milham S Jr. Demers RY. Mortality among pulp and paper workers. J Occup Med. 1984;26(11):844-6.

22. Hammar N, Alfredsson L, Smedberg M, Ahlbom A. Differences in the incidence of myocardial infarction among occupational groups. Scand J Work Environ Health. 1992;18(3):178-85.

23. Sala-Serra M, Sunyer J, Kogevinas M, McFarlane D, Antó JM. Cohort study on cancer mortality among workers in the pulp and paper industry in Catalonia, Spain. Am J Ind Med. 1996;30(1):87-92.

24. Wong O, Ragland DR, Marcero DH. An epidemiologic study of employees at seven pulp and paper mills. Int Arch Occup Environ Health. 1996;68(6):498-507.

25. Henneberger PK, Lax MB. Lung cancer mortality in a cohort of older pulp and paper workers. Int J Occup Environ Health. 1998;4(3):147-54.

26. Wild P, Bergeret A, Moulin JJ, Lahmar A, Hours M. Une étude de mortalité dans l'industrie Française du papier et de la pâte à papier [Mortality in the French paper and pulp industry]. Rev Epidemiol Santé Publique. 1998;46(2):85-92.

27. McLean D, Colin D, Boffetta P, Pearce N. Mortality and cancer incidence in New Zealand pulp and paper mill workers. N Z Med J. 2002;115:186-90.

28. Sunyer J, Ballester F, Le Tertre A, Atkinson R, Ayres JG, Forastiere F, et al. The association of daily sulfur dioxide air pollution levels with hospital admissions for cardiovascular diseases in Europe (the Aphea-II study). Eur Heart J. 2003;24(8):751-60.

29. Donaldson K, Mills N, Mac Nee W, Robinson S, Newby D. Role of inflammation in cardiopulmonary health effects of PM. Tox Appl Pharmacol. 2005;207(2 suppl): 483-8.

30. Analitis A, Katsouyanni K, Dimakopoulou K, Samoli E, Nikoloulopoulos AK, Petasakis Y, et al. Short-term effects of ambient particles on cardiovascular and respiratory mortality. Epidemiology. 2006;17(2):230-3.

31. Torén K, Bergdahl IA, Nilsson TK, Järvholm B. Occupational exposure to particulate air pollution and mortality due to ischemic heart disease and cerebrovascular disease. Occup Environ Med. 2007;64(8):515-9.

32. Bøggild H, Knutsson A. Shift work, risk factors and cardiovascular disease [review]. Scand J Work Environ Health. 1999;25(2):85-99.

33. Knutsson A, Akerstedt T, Jonsson BG, Orth-Gomer K. Increased risk of ischaemic heart disease in shift workers. Lancet. 1986;2:89-92.

34. Karlsson B, Knutsson A, Lindahl B. Is there an association between shift work and having a metabolic syndrome?: results from a population based study of 27485 people. Occup Environ Med. 2001;58(11):747-52.

35. van Kempen EE, Kruize H, Boshuizen HC, Ameling CB, Staatsen BA, de Hollander AE. The association between noise exposure and blood pressure and ischemic heart disease: a metaanalysis. Environ Health Perspect. 2002;110(3):307-17.

36. Virkkunen H, Kauppinen T, Tenkanen L. Long-term effect of occupational noise on the risk of coronary heart disease. Scand J Work Environ Health. 2005;31(4):291-9.

37. Virtanen SV, Notkola V. Socioeconomic inequalities in cardiovascular mortality and the role of work: a register study of Finnish men. Int J Epidemiol. 2002;31(3):614-21.

Received for publication: 23 October 2006 